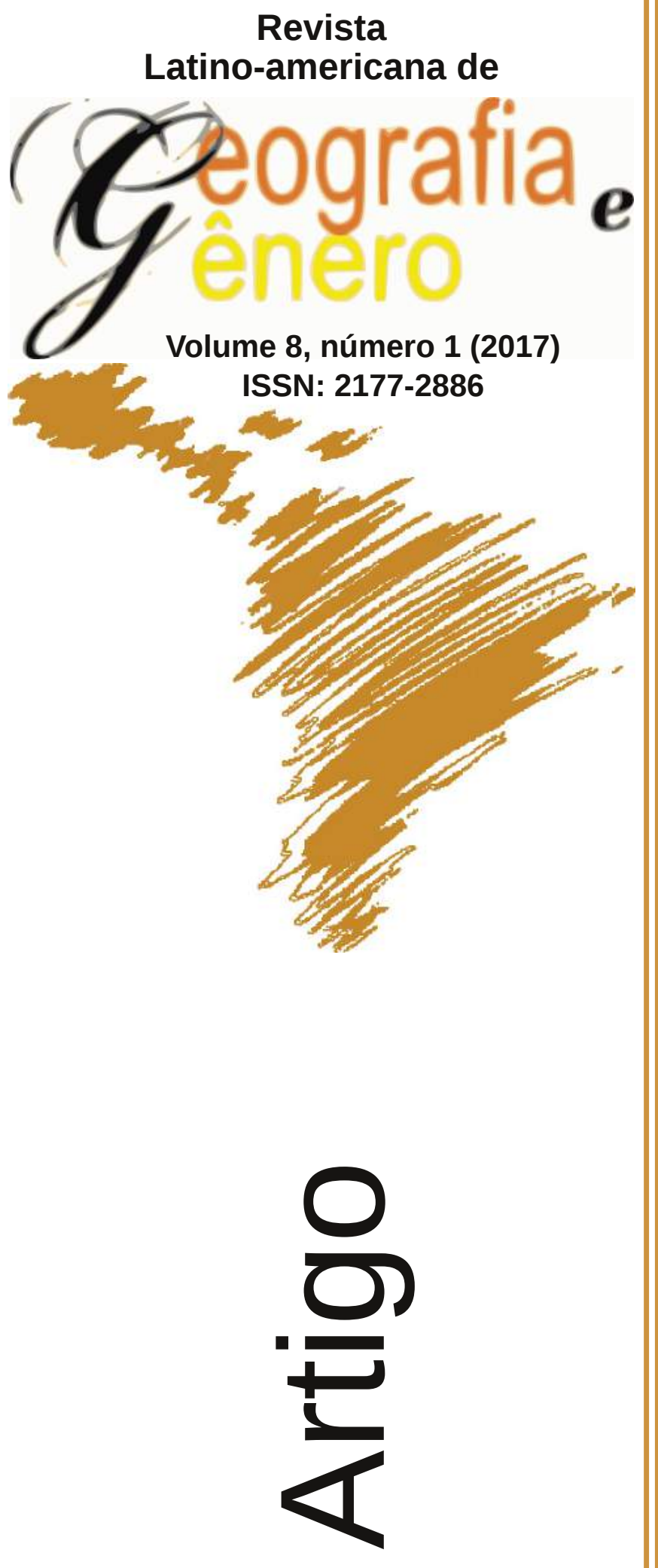

\title{
Gênero e Trajetórias Acadêmicas das Primeiras \\ Mulheres Universitárias Brasileiras
}

Género y Trayectorias Académicas de las Primeras Mujeres Universitarias Brasileñas

Gender and Academic Histories of the Firt Brazilian Graduated Women

Carmem Silvia da Fonseca Kummer Liblik Universidade Federal do Paraná - Brasil carmemsfk@gmail.com

Como citar este artigo:

LIBLIK, Carmem Silvia da Fonseca Kummer. Gênero e Trajetórias Acadêmicas das Primeiras Mulheres Universitárias Brasileiras. Revista Latino Americana de Geografia e Gênero, v. 8, n. 1, p. 104-125, 2017. ISSN 2177-2886.

Disponível em:

http://www.revistas2.uepg.br/index.php/rlagg 


\title{
Gênero e Trajetórias Acadêmicas das Primeiras Mulheres Universitárias Brasileiras
}

\author{
Género y Trayectorias Académicas de las Primeras Mujeres Universitarias \\ Brasileñas
}

\section{Gender and Academic Histories of the Firt Brazilian Graduated Women}

\begin{abstract}
Resumo
Gilda de Mello e Souza, Alice Canabrava, Olga Pantaleão, Jandyra Barzaghi, Maria Conceição de Carvalho e Veronica de Eston formam um grupo de mulheres que realizaram cursos superiores na Universidade de São Paulo no final da década de 1930, e consolidaram suas carreiras como professoras universitárias. Chamadas de "as pioneiras", essas profissionais nos deixaram depoimentos, escritos na década de 1980, os quais descrevem suas trajetórias acadêmicas e profissionais orientadas pelas questões de gênero. Por meio da análise do discurso, procuramos analisar esses testemunhos tendo como eixo norteador a entrada de mulheres em cursos superiores e as dificuldades iniciais que tiveram para consolidar suas carreiras em âmbito universitário brasileiro.
\end{abstract}

Palavras-Chave: Gênero; Pioneiras; Trajetórias Acadêmicas; Universidade de São Paulo.

\section{Resumen}

Gilda de Mello e Souza, Alice Canabrava, Olga Pantaleão, Jandyra Barzaghi, Maria Conceição de Carvalho y Veronica de Eston forman un grupo de mujeres que realizaron cursos superiores en la Universidad de São Paulo a finales de la década de 1930, y consolidaron sus carreras como profesoras universitarias. Llamadas como "las pioneras", estas profesionales dejaron declaraciones, escritas en la década de 1980, que describen sus trayectorias académicas y profesionales orientadas por las cuestiones de género. A través del análisis del discurso, se analizaron estos testimonios, teniendo como guía la entrada de las mujeres en la educación superior y las dificultades iniciales que tenían para consolidar sus carreras en el ámbito universitario brasileño.

Palabras-Clave: Género; Pioneras; Trayectorias Académicas; Universidad de São Paulo.

\begin{abstract}
Gilda de Mello e Souza, Alice Canabrava, Olga Pantaleão, Jandyra Barzaghi, Maria Conceição de Carvalho and Verônica de Eston form a group of women who had higher education at the University of São Paulo in the late 1930s, and had a solid career as university teachers and researchers. Called as pioneers, these professionals left us statements, written in the 1980s, which describe their academic and professional trajectories driven by gender. Through the analysis University of discourse, we analyzed these testimonies under the perspective of two events, namely: the admission of women in higher education and the initial difficulties they had face in order to consolidate their careers in the Brazilian university.
\end{abstract}

Keywords: Gender; Pioneers; Academic Pathways; of São Paulo. 


\section{Introdução}

A relação e o envolvimento das mulheres com o conhecimento científico e intelectual, e suas experiências como discentes e docentes nas universidades brasileiras consistem um tema relativamente recente no interior dos estudos de gênero nesse país. Busca-se compreender de que forma as relações de gênero se estabelecem entre alunos, alunas, professores, professoras e, principalmente, os caminhos trilhados pelas mulheres quando estas pretendem se tornar membro do corpo administrativo e docente universitário; e/ou pesquisadoras de grande visibilidade nacional (LIMA, 2002; TIBURI, 2002; AQUINO, 2006; BLAY, 2006; SANTOS, 2015). É comum, também, análises que refletem a maneira como o gênero pode ser uma importante categoria analítica que modelou o saber de algumas áreas científicas e profissionais. Além disso, saltase aos olhos de quem se interessa por esse tema a presença de discussões que tencionam a conciliação da vida profissional e acadêmica com a vida privada, a saber: casamento, família e filhos.

Nesse contexto, as trajetórias acadêmicas e profissionais das primeiras mulheres que ingressaram nos cursos da Faculdade de Filosofia, Ciências e Letras (FFCL) da Universidade de São Paulo (USP), em meados da década de 1930, constituem objeto de investigação desse artigo, cujos elementos serão problematizados pela análise do discurso. Para tanto, escolhemos os depoimentos das seguintes professoras universitárias: a filósofa Gilda de Mello e Souza; a química Jandyra França Barzaghi; as historiadoras Alice Canabrava e Olga Pantaleão; a geógrafa Maria Conceição Vicente de Carvalho e a médica Verônica Rapp de Eston. Seus testemunhos foram escritos no início da década de 1980, os quais revelam as experiências que tiveram na universidade a partir de 1934, ano em que a primeira delas, Jandyra França Barzaghi, ingressou no ensino superior. Um dos principais motivos que remetem à escolha destas profissionais incide no fato de terem sido as primeiras mulheres que concluíram cursos superiores na USP e trilharam suas trajetórias profissionais como professoras universitárias e pesquisadoras.

Mais do que isso, elas acompanharam a criação e institucionalização de alguns cursos da FFCL e, mais tarde, foram as principais representantes do sexo feminino, chamadas, então, de "as pioneiras", no desenvolvimento de pesquisas vinculadas à pós-graduação. Iremos analisar, portanto, seus depoimentos, nos quais constam descrições sobre a infância; o ingresso na universidade e o contato com as primeiras matérias e professores; a decisão de fazer doutorado; os concursos prestados para o cargo de Professora Titular e, por fim, as trajetórias como pesquisadoras. Por meio das ferramentas analíticas que o discurso no oferece, podemos perceber as maneiras como elas expressam as dificuldades de serem reconhecidas num espaço profissional que, em seu início, era predominantemente masculino. Nas próximas linhas, descrevemos uma breve biografia delas e, em seguida, analisaremos seus discursos conforme um eixo norteador dos mesmos, qual seja, as temporalidades que os regem.

Olga Pantaleão nasceu em Ariranha, estado de São Paulo, em 1917. Licenciou-se em Geografia e História pela FFCL da USP em 1938. Em 1944 tornou-se doutora em História pela mesma Faculdade. Entre 1939 a 1947 
assumiu o cargo de Primeira Assistente e depois Professora Interina da Cadeira de História da Civilização Moderna e Contemporânea. Foi fundadora do campus de Marília da UNESP e Professora Titular de História Moderna e Contemporânea na Faculdade de Filosofia, Ciências e Letras de Marília, de 1959 a 1975. De 1966 a 1976 foi Professora Visitante de História do Brasil e História da América Latina na Universidade de Indiana, Estados Unidos. Assumiu os cargos de Vice-Diretora da Faculdade de Filosofia, Ciências e Letras de Marília, de 1963 a 1965 e de Diretora da mesma Faculdade, de 1971 a 1975. Em sua carreira tornou-se, também, Sócia Titular do Instituto Histórico e Geográfico de São Paulo. Olga Pantaleão contribuiu com artigos relacionados à presença inglesa no Brasil, publicados na obra 'História Geral da Civilização Brasileira', organizada por Sergio Buarque de Holanda.

Alice Piffer Canabrava nasceu em Araras, estado de São Paulo, em 1911. Assim como Olga, licenciou-se em Geografia e História em 1938, pela FFCL. Doutorou-se em História em 1942, com tese em História Econômica. Quatro anos depois de conquistar o título de doutora, tornou-se Livre-Docente de História da Civilização Americana da FFCL e, em 1951, obteve título de professora catedrática de História Geral e do Brasil, da Faculdade de Economia e Administração da USP, exercendo função até 1981. Alice foi também uma das pioneiras no desenvolvimento de pesquisas voltadas à História Quantitativa e História Econômica na Universidade de São Paulo, além de ter sido uma das fundadoras da Associação dos Professores Universitários de História (ANPUH), bem como da Revista Brasileira de História (RBH).

A filósofa Gilda de Mello e Souza nasceu em São Paulo, em 1919, e passou boa parte da infância em Araraquara. Retornou a São Paulo em 1930 e ingressou na FFCL em 1937, bacharelando-se em Filosofia em 1940. A partir de 1942 foi Assistente de Sociologia do Professor Roger Bastide, ministrando cursos relacionados à Estética, disciplina que, mais tarde, passou a reger no Departamento de Filosofia. Em 1950, doutorou-se em Filosofia com a tese 'A moda no século XIX. Ensaio de sociologia estética'. Foi Professora-Chefe do Departamento de Filosofia, de 1960 a 1971 e fundou a revista Discurso, do Departamento de Filosofia, de 1970 a 1976.

Jandyra França Barzaghi nasceu em 1915, na cidade paulista de São Luiz de Paraitinga. Ingressou na USP em 1934, sendo aluna da primeira turma da Faculdade de Filosofia, Ciências e Letras, admitida na área de Química da Faculdade recém-criada. Antes disso, diplomou-se em 1930 pela Escola Normal de Pirassununga e em 1933 foi nomeada "preparadora de Física e Química" no magistério primário. Em 1938, concluiu a licenciatura na FFCL em Química e prosseguiu os estudos ao fazer o doutorado sob a orientação do professor alemão Heinrich Hauptmann. Em 1942, defendeu a tese "Sobre o Cafesterol e alguns de seus derivados", tendo sido aprovada com distinção, quando já exercia o cargo de Assistente da Cadeira de Química Orgânica e Biológica. Nos anos posteriores foi uma das responsáveis por organizar o curso de Química da USP e pediu desligamento em 1951, por motivos particulares.

A geógrafa Maria Conceição Vicente de Carvalho nasceu em Santos, em 1906. Licenciou-se em Geografia e História pela Faculdade de Filosofia, 
Ciências e Letras da Universidade de São Paulo, em 1938. Doutorou-se com tese em Geografia em 1943 e foi membro do Conselho Nacional de Geografia, com sede no Rio de Janeiro, em 1946. Foi bolsista do governo francês, na Universidade de Paris, de 1951 a 1952 e professora de Geografia Humana na Universidade Católica do Rio de Janeiro, de 1948 a 1958. Por fim, foi Professora Titular de Geografia no curso de História da Faculdade de Filosofia, Ciências e Letras da Universidade Júlio de Mesquita Filho, Campus de Marília, de 1959 a 1972.

Finalmente, apresentamos a médica Verônica Rapp de Eston, nascida em São Paulo, em 1918. Formou-se em Medicina pela Universidade de São Paulo, em 1944. Após dois anos de cursos, estágios e pesquisas nos Estados Unidos e Canadá, com bolsas de estudo, ingressou no Departamento de Química Fisiológica da Faculdade de Medicina da Universidade de São Paulo. Exerceu o caro de Chefe da Divisão de Ensino e Pesquisas Biológicas, ministrando cerca de quarenta cursos de Pós-Graduação. Foi aprovada no concurso de Livre-Docência no Departamento de Química Fisiológica da Faculdade de Medicina da Universidade de São Paulo, em 1958, tornando-se a primeira mulher Livre-Docente desta faculdade. Foi fundadora e secretária da Sociedade Brasileira de Biologia e Medicina Nuclear e da Associação LatinoAmericana de Sociedades de Biologia e Medicina Nuclear. Foi presidente da Associação Brasileira de Mulheres Médicas em âmbito regional e nacional, aposentando-se em 1976, após 30 anos de serviços prestados à Universidade de São Paulo.

Cabe observar que estaríamos tratando com vencedoras, aqui consideradas pioneiras. Certamente havia outras que chegaram à mesma posição e ainda aquelas que se formaram, mas não seguiram a carreira docente na universidade, ou aquelas que reorientaram suas vidas seguindo outras opções. A seleção dos depoimentos e a escolha destas profissionais incidem, como iremos explicar nas próximas linhas, no contexto de produção de seus discursos, escritos e comunicados em 1984.

\section{A Primeira Temporalidade: As Condições de Produção dos Depoimentos e Seus Significados}

Os depoimentos foram escritos em julho de 1984, em função da comemoração dos 50 anos da fundação da USP e da Faculdade de Filosofia, Ciências e Letras. Quem conduziu todo o processo de entrar em contato com as ex-alunas, solicitar seus depoimentos, realizar a transcrição dos mesmos e, por fim, organizá-los em diferentes edições foi a historiadora Eva Alterman Blay. O objetivo desta historiadora foi o de reunir depoimentos das primeiras alunas da USP que, mais tarde, consolidaram suas carreiras acadêmicas no ensino superior como pesquisadoras e professoras. Os testemunhos foram fornecidos em 1984, quando as pioneiras tinham em torno de 70 anos de idade e se aposentado há alguns anos da universidade. Finalmente, a apresentação de suas experiências como alunas e docentes na FFCL da USP aconteceu na reunião da $36^{\text {a }}$ Sociedade Brasileira para o Progresso da Ciência (SBPC), em 1984. Neste evento, estas mulheres foram, então, chamadas de "as pioneiras". Alguns trechos dos depoimentos foram publicados em um artigo redigido por 
Eva Blay e Alice Gordo Lang, intitulado "A mulher nos primeiros tempos da Universidade de São Paulo" na revista Ciência e Cultura, e depois disso o material foi arquivado por motivos diversos. Passados 20 anos, algumas fotos, as informações das entrevistas preliminares e os relatos foram organizados em um livro publicado por Eva Blay e Alice Lang, intitulado Mulheres na USP: Horizontes que se abrem.

O conjunto de narrativas memorialísticas e autobiográficas vem ao encontro da necessidade de professoras e pesquisadoras universitárias de externar experiências passadas, muitas vezes difíceis e conflituosas, no contexto da inauguração dos primeiros cursos superiores da FFCL. Os depoimentos estão situados nos limites do discurso, autobiografia e memória. São registros feitos no ano de 1984 que trazem, pelos fios da memória, as experiências que as universitárias tiveram como alunas e professoras a partir de meados da década de 1930, momento da criação da FFCL. Devido ao propósito da historiadora Eva Blay, em organizar os depoimentos somente de ex-alunas da USP que se tornaram professoras e pesquisadoras universitárias, parte dos acontecimentos narrados trata do processo de entrada das mulheres na universidade, a sociabilidade entre as moças e rapazes universitários, a relação que as pioneiras tiveram com seus professores e as dificuldades que enfrentaram nos primeiros anos da vida profissional. Logo, seus discursos alinham-se, especificamente, a um eixo central de produção de conteúdo mediado pela memória: as experiências femininas no âmbito universitário, ora como alunas, ora como professoras.

São discursos que se afastam do presente e se lançam para o passado. Por meio de critérios diversos, as intelectuais em questão selecionaram, organizaram e sistematizaram situações que foram vivenciadas conforme o estabelecimento de um objetivo comum: trazer as relações de gênero para o interior do espaço universitário. Elas politizam a universidade, os cursos e suas trajetórias profissionais trazendo o gênero como chave norteadora de compreensão de tais processos.

É interessante notar que os depoimentos das pioneiras estão articulados a duas temporalidades. A primeira diz respeito ao próprio período em que discursos foram escritos e apresentados, ou seja, no início da década de 1980. É justamente neste período, ou melhor, a partir da década de 1970, que os estudos de gênero, a história das mulheres e as teorias feministas são recebidos por pesquisadoras que trabalham em universidades brasileiras, principalmente a USP. A partir de então, surgem os primeiros estudos sobre a condição das mulheres no Brasil, baseados nos debates teóricos iniciados principalmente na França e Estados Unidos. Mesmo considerando o fato de que as professoras universitárias não se intitularam como feministas e não pesquisaram temas relativos ao gênero ou às 'mulheres', elas não estavam alheias a este processo.

Sabe-se que na década de 1970, em São Paulo, alguns grupos formados por professoras universitárias se organizavam em âmbito privado para discutir e fazer leituras feministas. Discutiam as várias etapas da vida das mulheres, a sexualidade, o casamento, a relação com os homens. A historiadora Maria Odila Leite da Silva Dias, por exemplo, era componente de um grupo que se chamava "grupo de conscientização feminista". Elas se reuniam periodicamente na residência de uma pessoa e faziam leituras feministas, 
orientadas por livros trazidos da França e Estados Unidos (PEDRO, 2011, p. 51). A par disso, no Brasil, o ano de 1975 tem sido considerado como ano fundador do feminismo, motivado e estimulado pela declaração da ONU como sendo este o Ano Internacional da Mulher, e também o início da Década da Mulher. Como aponta a historiadora Joana Maria Pedro, estes acontecimentos - a reunião que ocorreu na Associação Brasileira de Imprensa (ABI) e a criação do Centro da Mulher Brasileira (CMB), no Rio de Janeiro -, são pensados como marcos fundadores do feminismo no Brasil (PEDRO, 2011, p. 51-56).

As universitárias em questão estavam inseridas num espaço institucional que começou a receber e a produzir os primeiros trabalhos da área e, por consequência, direta ou indiretamente, socializaram com pesquisadoras feministas e transitaram nos mesmos espaços que elas. A partir de suas vivências, mediadas, então, pelos debates feministas que adentraram nas universidades públicas do país no início da década de 1970, é que a memória delas pode construir significados e elaborar interpretações em relação às experiências pretéritas. Dificilmente elas teriam consciência e configurado os mesmos sentidos às suas vivências se as tivessem narrado nas décadas de 1930, 1940 ou 1950. É dessa maneira que podemos entender a constituição dos significados inerentes ao depoimento das pioneiras em questão, ou seja, reconhecendo suas condições de produção. Como afirma Eni Orlandi, "falar em discurso é falar em condições de produção", nas quais constam os lugares sociais dos interlocutores e sua posição relativa no discurso (ORLANDI, 1983, p. 146).

As primeiras páginas do discurso de Alice Canabrava, por exemplo, remetem ao momento histórico em que ela o redigiu, o qual foi fundamental para a escolha dos temas abordados no texto, especialmente aqueles articulados com as dificuldades que teve na vida profissional por ser mulher. Ela desenvolve, inicialmente, noções relativas a uma sociedade preconceituosa com as mulheres, em que "em sua grande maioria [elas] permanecem, na História, como figuras silenciosas, em grande parte, obscuras, mães, esposas ou filhas sem voz própria". A historiadora lembra a mulher como "figura silenciosa", impedida por muito tempo de comunicar sua própria visão de mundo, de modo que os depoimentos femininos são relativamente "raros na literatura histórica brasileira". Enfatiza que, somente nos últimos anos, surgiram iniciativas que procuram "resgatar" a memória feminina.

No entanto, ela procura não generalizar e dizer que todos os homens comportavam-se da mesma maneira com o sexo oposto no âmbito universitário. Para a historiadora, apesar de não fazer menções, "excelentes pessoas situavam-se dentro do seu tempo e do seu meio". Então ela tem a consciência de distinguir as pessoas que se opuseram à sua carreira daquelas que não tiveram comportamentos hostis. Tampouco se faz de vítima singular que enfrentou solitariamente as dificuldades colocadas, uma vez que ela percebia as discriminações que acometiam a vida de outras mulheres universitárias. As primeiras linhas de seu testemunho são dedicadas para, primeiramente, esclarecer que não conservou nenhum ressentimento àqueles que lhe foram hostis e, segundo, situar o contexto social e histórico inerente a sua trajetória profissional: 
Não conservei ressentimento com respeito aos que se opunham à minha ascensão na Universidade. Excelentes pessoas situavam-se dentro do seu tempo e do seu meio, expoentes de uma sociedade preconceituosa para com as mulheres. Não se suponha que tenha sido eu, o único alvo da discriminação: esta visava a todas. No meu caso, a resistência provocou o desenrolar de todo o processo. Em outros, este se interrompeu ou nem foi acionado, dado o afastamento da interessada, seja voluntário, seja imposto pelas circunstâncias. Por outro lado, pareceu-nos que é possível descortinar, nos anos 70, as evidências do esmorecer das barreiras contra as mulheres na Faculdade de Filosofia, com a aceitação de sua atividade como realização profissional, consubstanciada em carreira acadêmica, propiciada, senão imposta, a todos os docentes, pela reforma universitária. Entretanto, sou informada aqui, de que a oposição masculina subsiste em outros setores da Universidade. A luta não está finda. (CANABRAVA, p. 17, 2003)

Da mesma forma, Olga Pantaleão também articula suas memórias com as dificuldades que enfrentou no início de sua vida profissional. Apesar de ter sido contratada como Primeira Assistente da Cadeira de História Geral, indicada pelo Professor Gagé, o qual sempre lhe deu 'total apoio', ela narra que:

Então, as coisas começaram a mudar. Uma reação masculina contra as mulheres começou a se manifestar por força de vários fatores: quando a mulher se mostrava mais competente do que os homens do mesmo campo de estudo e de ensino, quando ocupava ou passava a ocupar lugar desejado por algum colega do sexo masculino, ou pela simples razão do preconceito antifeminista. Não posso dizer que era uma situação geral na Faculdade: houve colegas nossas que nunca foram inquietadas e puderam permanecer pelo tempo que quiseram nos seus postos. Mas, em certo momento, instalou-se em alguns setores uma atitude antifeminista bem marcada. Na História, por exemplo, um de seus professores falava ser preciso por o "mulherio" para fora da Faculdade (PANTALEÃO apud BLAY; LANG, p. 112, 2004).

Assim como Alice Canabrava, Olga Pantaleão não especifica como foi essa "reação masculina contra as mulheres". Seria uma reação por parte dos colegas de turma? Ou seriam, sobretudo, os professores catedráticos que não desejavam compartilhar suas Cadeiras com as jovens moças recém-formadas? Não é possível saber, exatamente, que tipo de hostilidades elas sofreram, nem o quanto isso impactou e modelou suas carreiras. No entanto, o que chama a atenção na fala de Olga é o emprego do termo "antifeminismo". Seria possível os homens de sua época serem compreendidos a partir de suas atitudes 
antifeministas? Cremos que não, justamente porque as alunas daquela época não eram feministas e porque as "ações masculinas" não se direcionavam a uma luta feminista.

Aqui, percebe-se algo interessante que pode ser compreendido à luz da intertextualidade. Olga, quando escreveu seu testemunho no início da década de 1980, atravessou algumas gerações de professoras e pesquisadoras, compareceu a reuniões que visavam formar uma associação de mulheres universitárias e, inclusive, narrou suas experiências articuladas a um determinado fio condutor: a "luta das pioneiras". Por isso ela aplica o conceito "reação antifeminista", recentemente adquirido à época, como modelo para compreender e dar sentido aos comportamentos masculinos do passado.

O fato é também que Olga Pantaleão produz linguagem e também está reproduzida nela, acreditando ser a fonte exclusiva do seu discurso quando, na verdade, o seu dizer nasce também a partir de outros discursos. Neste caso, trata-se até de reconhecermos o conjunto total dos testemunhos que foram dados pelas mulheres que ingressaram na USP na década de 1930 e que lá trilharam suas carreiras acadêmicas. Suas palavras, portanto, são partes de formações discursivas. Afinal, como afirma Eni Orlandi, "as formações discursivas determinam o que pode e deve ser dito a partir de uma posição dada em uma conjuntura dada, assim é que se considera o discurso como fenômeno social" (ORLANDI, 1983, p. 146).

Alice Canabrava nos informa logo no início que deixou "correr os dedos na máquina de escrever, ao leve toque das reminiscências" e que não "omitiu alguns pormenores que me pareceram significativos para caracterizar o ambiente". Paradoxalmente, na mesma frase ela deixa claro que outras informações, também importantes, ficariam para um possível livro autobiográfico, que na verdade nunca chegou a ser escrito. Estas passagens são propícias para pensarmos no que Michel Foucault explicou sobre a interdição da palavra, isto é, de que maneira podemos pensar a definição do que pode ser dito, ou não dito, dependendo de cada circunstância. Na interdição, "não temos o direito de dizer o que nos apetece, não podemos falar de tudo em qualquer circunstância, quem quer que seja não pode falar do que quer que seja" (FOUCAULT, 1998, p. 7). Alice Canabrava é uma historiadora que tinha a consciência de que seu depoimento seria lido por um determinado público: a de historiadores; sejam alunos ou professores. São seus pares profissionais, com os quais ela, mesmo aposentada, mantinha relações e redes de contato. Além disso, há de se considerar a preocupação de todo intelectual, independente da área que atua, em preservar uma imagem pública sólida e respeitável mediante seus pares de trabalho.

Por isso, nem tudo pode ser falado, exposto e revelado. Ainda para Foucault, é sabido que as regiões onde "a grelha mais se aperta, são as regiões da sexualidade e as da política" (FOUCAULT, 1998, p. 8). O discurso de Alice Canabrava, aparentemente, pode até "nem ser nada" - como diz Foucault, no entanto, os interditos que o atingem revelam de imediato o seu vínculo a acontecimentos que podem remeter a companheiros de trabalho, situações conflituosas no meio profissional, disputas, enfim, afetos e desafetos no espaço universitário. Exemplo disso é notado quando ela narra as dificuldades que lhe apareceram no início de sua vida profissional. Ao concluir sua tese de 
doutorado intitulada $\mathrm{O}$ comércio português no Rio da Prata, Alice conta que "mereceu elogios da crítica nacional e estrangeira, publicados em revistas internacionais". Com efeito, sem fazer menções ou detalhar ocorrências cujos "personagens masculinos" the foram hostis, ela apenas informa que o relacionamento com os colegas homens mudou depois que recebeu louvores à sua tese:

Deste modo, involuntariamente, emergi, aos olhos dos meus colegas masculinos, como possível candidata ao provimento efetivo da cadeira de História da América, a ser posta em concurso. Até então, o relacionamento com esses colegas havia sido muito afável, direi até, não isento de estima pessoal. A partir de então, o círculo de hostilidade subterrânea começou a se desenhar para mim com evidências, a se apertar anonimamente em uma ou outra ocorrência da atividade universitária, sem alterar a aparência da superficial cordialidade (CANABRAVA, 2003, p. 19).

As pioneiras se colocam no papel de agentes que irão narrar suas experiências do passado. É dessa maneira que elas constroem a cenografia de sua autoridade enunciativa. Ao se enunciar, elas estabelecem uma espécie de "ritual social da linguagem", que, nesse caso, é a linguagem inerente ao próprio campo de trabalho do historiador. Nesse sentido, Dominique Maingueneau nos oferece uma pista para entender a posição de sujeito enunciador que as pioneiras ocupam em relação aos seus interlocutores: a enunciação produzida por um sujeito é colocada em contato que lhe credita o lugar de detentor do saber. Elam possuem a legitimidade do lugar que ocupam neste processo enunciativo, sendo que seus enunciatários são estudantes ou professores universitários (MAINGUENEAU, 1989, p. 30). Por extensão, as professoras universitárias definem em vários momentos do texto, como veremos a seguir, os seus "lugares da verdade", ou seja, elas inserem informações que as legitimam como influentes profissionais que ocupam o lugar do saber.

\section{A Segunda Temporalidade: Reflexões sobre um Passado não tão Distante Assim}

A segunda temporalidade presente nos depoimentos refere-se à constituição de um devir marcado pela trajetória de vida, particularmente aquela vinculada às experiências acadêmicas, cuja preocupação por parte das universitárias seria narrar os acontecimentos que lhes foram mais caros, obedecendo uma ordem cronológica e linear. Esse tempo tem início na infância, no caso de Gilda de Mello e Souza, Jandyra França Barzaghi, Alice Canabrava, e finda nas conquistas profissionais, por parte de todas elas. É nesse sentido que as pioneiras narram suas histórias de vida, tecendo os fios das lembranças, as quais se misturam, se organizam e se somam de forma que um acontecimento, uma pessoa ou um afeto conduzem à memória de outros eventos que foram importantes. 
Se Olga Pantaleão, Maria Conceição Vicente de Carvalho e Verônica Rapp de Eston não compartilham suas histórias familiares, pois iniciam os depoimentos somente a partir do momento em que ingressaram na FFCL, as outras pioneiras não poupam informações a respeito de suas histórias pessoais condizentes à infância que tiveram nas cidades do interior de São Paulo. O efeito de sentido causado por esse recurso narrativo é claro: expressar que o ingresso na FFCL foi um divisor de águas na vida delas. Com essa divisão, fica claro que havia um "antes", período no qual elas viviam como toda mulher da época vivia, ou seja, imersas em um ambiente tradicional, religioso e patriarcal, apesar de suas tensões com a presença de novos modelos de comportamento femininos; e um "depois", momento assinalado como um mergulho em novos horizontes, principalmente os culturais e profissionais, que a universidade promoveu na vida dessas mulheres.

Passando parte da infância em Araraquara, Gilda de Mello e Souza se inscreveu no curso de Filosofia em 1937, aos 17 anos de idade. Sua formação escolar se limitava ao ginásio e ao segundo ano pré-universitário, que acabara de cursar na Faculdade de Direito. Conta que, desde os 12 anos, vivia num ambiente: "generoso e hospitaleiro que, desde o século passado, vinha servindo de ligação entre o campo e a capital e abrigando gerações sucessivas de parentes mais rústicos, em demanda de ensino e polimento". Gilda de Mello e Souza qualifica o ambiente familiar no qual cresceu por ser sui generis: por um lado, havia os hábitos interioranos mantidos pelos mais velhos; por outro, havia a presença de parentes que traziam novos livros para a biblioteca, os quais foram decisivos para sua formação:

Por essa razão, eu já era aos 18 anos uma menina inquieta, minada pela disputa entre o velho e o novo, dilacerada entre o estilo patriarcal, que imperava na casa, e o apelo novo de vida que a biblioteca propunha. As conversas esparsas com meu primo, nos intervalos das lições de piano; a análise das minhas primeiras tentativas literárias, que ele empreendeu com minúcia comovente; a discussão do que eu pretendia ser na vida - tudo isso amadureceu em nós dois a convicção de que eu deveria me inscrever na Faculdade, de preferência no curso de Filosofia (SOUZA apud BLAY; LANG, 2004, p. 65).

Assim como Gilda de Mello e Souza, Jandyra França Barzagui também descreve o cenário onde passou os anos da juventude, na cidade de Pirassununga. Como boa parte das mulheres que pretendiam ter uma profissão, estudou o Curso Normal para ser professora do ensino primário, lembrando-se de que, naquela época, o código moral imposto às mulheres sempre obedecia aos lemas "mulher não deve" ou "mulher não pode". Mudou-se para São Paulo em 1934, apesar de que as restrições familiares ainda continuavam:

O viaduto do Chá era então lugar proibido depois das seis horas da tarde; sair à noite, somente em grupos ou acompanhada por um irmão. Namorar, só com "vela" credenciada devidamente. Lembro-me de um 
namoro terminado na família, porque o irmão mais velho encontrara a irmã tomando chá, sozinha com um rapaz, numa confeitaria do bairro. Eu já era assistente da faculdade e meu irmão, geógrafo (Prof. Dr. Ary França), assistia por obrigação familiar a todas as conferências de química a que eu comparecia (BARZAGUI, 2004, p. 77-78).

Alice Canabrava, por sua vez, nasceu em Araras e, nesta cidade, dedicou-se durante quatro anos ao ensino primário, lecionando no grupo escolar local, o único do município. Ela chegou a trabalhar também, em 1931, em Manduri, um "lugarejo em meio a um grande campo arenoso", onde havia apenas uma rua central, mas sem cinema, médico ou praça que pudessem remeter à estrutura de um centro urbano. E finalmente, "transferida para Araras, minha terra natal, fui encontrá-la estagnada como a havia conhecido na minha infância". Era uma cidade pequena, "dilacerada por lutas políticas", que dificultava progressos profissionais ou acadêmicos para a jovem estudante. Sem muitas perspectivas de crescimento pessoal e profissional, e intimamente "sempre inconformada", Alice Canabrava folheava diariamente as páginas do Diário Oficial, em busca de uma oportunidade para se mudar para São Paulo e continuar a estudar.

Possivelmente, estas informações são fornecidas para atender a um objetivo discursivo: intentam mostrar o ambiente familiar em que as pioneiras se situavam, afastadas da capital do estado, absorvidas numa área de trabalho muito diferente daquela que iriam futuramente escolher. Nessa mesma direção, a própria Alice Canabrava chama atenção para o fato de que estas lembranças podem parecer muito afastadas do propósito que reuniu as pioneiras na reunião da SBPC em 1983. Mas, como ela diz, tais lembranças "não significam narrativa vã", pois intentam mostrar o "ambiente em que me movia, afastada da capital do estado, absorvida em área de trabalho muito diferente daquela que iria escolher, ao entrar para a Faculdade".

Para compreendermos os motivos que levaram Alice Canabrava, Gilda de Mello e Souza e Jandyra França Barzaghi a introduzir as memórias de sua infância e adolescência, a especialista em análise do discurso e crítica cultural, Leonor Arfuch, traz à luz a temática da genealogia no interior das biografias. Ou seja, nenhuma posição de enunciação advém "de graça" no espaço discursivo da fala de quem tece sua própria biografia: o desafio é justamente achar uma voz autobiográfica que possa dar sentido a um mito de origem, a uma genealogia, a um devir predestinado. Por isso, o espaço biográfico - a narração de histórias e experiências, a captação de vivências e lembranças opera, completamente, nesse "resgate" do próprio local de origem (ARFUCH, 2010, p. 60).

Nessa mesma direção, Benito Schmidt também chama atenção para o fato de que em muitos trabalhos biográficos, é possível perceber que os autores buscam na infância e/ou na adolescência uma espécie de predestinação para suas atividades futuras (SCHMIDT, 2000, p. 58). Dito de outra maneira, a vivência no interior de São Paulo e suas limitações, a presença de um "espírito curioso e inquieto", a tensão que enfrentaram por conviverem entre o "velho" e o "novo", estão relacionadas aos motivos que impulsionaram essas mulheres a 
irem para a capital do Estado e decidir por um Curso Superior. A falta de possibilidades na carreira, estímulo e crescimento nessas cidades lhe causavam grandes inquietações que deveriam ser superadas por meio da educação e trabalho. Por isso, nota-se no início de todos os depoimentos, relatos sobre as limitações profissionais impostas às mulheres e a opressão da sociedade patriarcal que as impedia de circular nos espaços públicos, como aponta a geógrafa Maria Conceição Vicente de Carvalho:

Numa sociedade patriarcal, como a paulista de então, muito preconceituosa quanto ao trabalho das mulheres fora de casa, o ensino primário era o campo de trabalho quase exclusivo que lhes era oferecido. Poucas ousavam aventurar-se fora deles, arrostando inscrever-se na Faculdade de Direito, e menos ainda, na da Medicina ou Engenharia. E, mesmo estas, nem sempre seguiram a profissão (CARVALHO apud BLAY; LANG, 2004, p. 119).

Outro tema abordado, nos depoimentos aqui tratados, refere-se ao número crescente da entrada de mulheres nos cursos da FFCL, especialmente o de Geografia e História. Nessa direção, podemos falar que houve um processo de feminização nesse curso a partir da década de 1930? A resposta é definitivamente positiva se considerarmos o amplo acesso e estímulo que as mulheres receberam do governo do país para ingressarem nos cursos da FFCL. A necessidade do Estado de preparar professores para o ensino médio, em expansão no país, levou os governos estaduais a recorrer, a partir de 1935, ao comissionamento, por meio do qual professoras e professores primários em exercício do magistério poderiam cursar a faculdade, sem prejuízo dos vencimentos, subsidiados pela Secretaria da Educação (BLAY, 2004, p. 51). Esta foi a primeira política pública implementada na Universidade de São Paulo, um ano após sua criação.

$\mathrm{O}$ regime de comissionamento foi um dos fatores determinantes para a inclusão de alunos e alunas provenientes de diferentes condições socioeconômicas de várias faixas etárias, de mulheres e homens, de portadores de diplomas diversos. O corpo discente, já a partir do segundo ano de funcionamento da FFCL da USP, passou a incorporar setores da classe média, pessoas vindas do interior do Estado, famílias ligadas ao magistério, famílias tradicionais empobrecidas e, sobretudo, mulheres (TRIGO, 1997, 68-9, 77). Embora essa política tivesse como principal objetivo a formação de profissionais para a educação primária e secundária, essa ação teve outra consequência, não previamente planejada: o regime de comissionamento permitiu uma presença significativa de mulheres na FFCL, já que estas representavam a maioria das egressas das Escolas Normais do Estado. Uma nova realidade para a época, quando era pouco comum a presença das mulheres no ensino superior do Brasil.

Essa afirmação fica mais evidente quando se analisa a seção de Geografia e História, que não apresentava nenhuma mulher entre os 16 matriculados em 1934. Porém, conforme o Anuário da FFCL, em 1935, ano em que o decreto passa a vigorar, há 16 matrículas femininas, num total de 29. Nos anos 
seguintes, o número de mulheres continua a exceder o número de homens. A seção de Filosofia também reflete essa realidade: há 12 matrículas femininas no ano de 1935, num total de 27, contra apenas uma mulher matriculada num universo de 46 matrículas no ano anterior (BLAY, 2004, p. 53). Foi por meio do comissionamento que as pioneiras conseguiram entrar na FFCL, cujo acontecimento é notadamente enfatizado em seus depoimentos e relacionado às certas dificuldades e preconceitos com as mulheres:

A Faculdade, desde a sua segunda turma, foi invadida pelas mulheres em quase todos os seus cursos, constituindo-se num caso à parte no conjunto da Universidade: as outras Escolas Superiores acolhiam muito poucas mulheres e algumas lhes estavam ainda fechadas, principalmente por causa dos preconceitos existentes na sociedade. Essa entrada das mulheres na Filosofia foi permitida por vários fatores: pela abertura dos vestibulares aos egressos das Escolas Normais, pelas facilidades, como os comissionamentos, dadas aos professores primários para fazerem os cursos, pelo fato de a nova Faculdade não estar submetida aos preconceitos da época e pela diversidade de cursos oferecidos, a acenar com novas carreiras ao alcance das mulheres dos idos de 1930 (PANTALEÃO apud BLAY; LANG, 2004, p. 109).

Esse decreto, além de promover uma melhoria no ensino primário estadual, também teve uma consequência não prevista pelos autores da medida: a oportunidade de um caminho para o ingresso de mulheres na universidade pública. Aberta essa possibilidade, muitas delas decidiram seguir a carreira acadêmica, refutando qualquer ideia ou iniciativa de trabalhar no ensino primário ou secundário. A FFCL significou para as pioneiras uma ampla e real oportunidade de ingresso no ensino superior. Como afirma Jandyra Barzagui: "evidentemente, não se cogitava que as mulheres pudessem desejar estudar, senão na Escola Normal, e as poucas que o faziam eram pioneiras que arduamente cavavam seu lugar entre os homens". Abria-se um espaço e uma oportunidade para trilhar novos caminhos, em especial uma vida intelectual, em meio a uma sociedade que preconizava um modelo tradicional e conservador para a mulher: casamento, lar e filhos.

Ao ingressar na Faculdade de Filosofia, Ciências e Letras da Universidade de São Paulo, em 1935, para frequentar os cursos de Geografia e História, Alice Canabrava sentiu-se "inquieta ante a grandeza dos mestres da instituição, mas profundamente entusiasmada". Os mestres, o conteúdo dos cursos e a metodologia de ensino significaram para ela uma "verdadeira mutação" em sua vida. Representavam um salto enorme em relação ao tipo de ensino que havia recebido na Escola Normal, pois o curso superior lhe permitiria "refletir a vida cultural do país e a proporcionar uma visão do mundo completamente nova”. É curioso notar que as outras depoentes utilizam termos e expressões muito semelhantes para se referirem à primeira impressão que tiveram quando ingressaram na USP. Gilda de Mello e Souza destaca que era uma das alunas 
mais jovens da sua turma e que acolheu "com entusiasmo aquela aventura extraordinária, que me atirava, do dia para a noite, na instigante atmosfera intelectual de uma faculdade tipicamente europeia”. Jandira França Barzagui, por sua vez, narra o seguinte:

(...) maravilhosos professores os que nos foram destinados! Aulas teóricas experimentais brilhantes, que eram abertura para ilimitados conhecimentos, verdadeiramente apaixonantes, a que assistíamos por mais de 2 horas sem perceber, que deixávamos com pena, que ansiávamos por tornar a ouvir; o contato primeiro com a pesquisa científica, que não media esforços nem contava as horas, aquela dedicação e aquele esforço além das forças, que levaram meu saudosíssimo Prof. Dr. Heinrich Hauptmann à morte tão prematura; as aulas práticas de dia inteiro, em que permanecíamos em estreita camaradagem com professores e colegas. Eram tempos mágicos aqueles (BARZAGUI apud BLAY; LANG, 2004, p. 82).

"Tempos mágicos", "aventura extraordinária", "instigante atmosfera intelectual", são expressões que provocam um importante efeito de sentido. Não apenas as pioneiras, mas podemos afirmar que praticamente todos os primeiros alunos e alunas da USP externaram um profundo entusiasmo e reconhecimento pelo contato que tiveram com um novo modelo didático exposto nas aulas dos professores europeus. Era, para eles e elas, uma revolução no ensino se comparado ao que tinham aprendido no ensino Normal, Clássico ou Científico. A inovação não se resumia ao tipo de aulas que era dado, mas como afirma Eva Blay, "ao conteúdo e à relação que se estabelecia entre os professores e alunas(os)" (BLAY \& LANG, 2004, p. 10). Uma nova e diferente sociabilidade estava sendo vivenciada por essas mulheres que até então tinham seus círculos de sociabilidade restritos à família.

O espaço universitário que estava sendo criado na década de 1930 tinha a característica de abarcar elementos diferentes em relação aos padrões vigentes de espaço e sociabilidades da época. Para o(a) aluno(a), esse processo significava inserir-se, como informa Graziela Perosa, num espaço público, misto, fora do restrito controle moral imposto pela religião e pelas famílias, no qual as mulheres estariam expostas à influência de um ambiente intelectual, laico e à convivência com jovens de origens sociais e culturais diferentes (PEROSA, 2005). O intercâmbio e as amizades consolidadas entre alunos e alunas são relembrados por Gilda de Mello e Souza e Veronica Rapp de Eston da seguinte maneira:

O novo convívio... Noutra oportunidade talvez eu fale mais demoradamente na atmosfera maciçamente francesa em que vivíamos, no fascínio exercido sobre nós pelos professores, o qual, extravasando as aulas, prolongava-se pelas conversas, nos intervalos dos cursos; e na influência dos próprios colegas uns sobre os outros. Tudo era discutido em comum e com entusiasmo: as leituras, as revelações artísticas, os projetos. Quantas vezes, à tardinha, saindo 
das aulas, prosseguíamos em bando pela cidade, à cata de algum filme, para terminar a noite defronte de um tranquilo milk-shake, entoando as velhas canções francesas recentemente aprendidas. Tudo isso deve parecer muito antigo para a juventude hoje (SOUZA apud BLAY; LANG, 2004, p. 68).

Jovens e adultos de vários níveis da classe média e estudantes da alta burguesia tinham em comum a convivência com os mesmos professores e com os grupos reunidos em conferências, bares, associações estudantis. Alunos vinham de outras escolas como a Engenharia, a Medicina e o Direito para encontrar na "Filosofia" o ambiente político de que careciam em suas Faculdades. (...) Foi neste ambiente que as mulheres puderam, pela primeira vez em número considerável, frequentar um curso superior junto a colegas do sexo masculino. Jovens burguesas saíam das aulas de chapéu e luvas e se encontravam com novas estudantes de Química, Matemática, Filosofia, História ou Geografia, despojadas de marcas de classe em suas vestes. Isto marcou os dois grupos (DE ESTON apud BLAY; LANG, 2004, p, 131).

A época estudantil das pioneiras é contada como uma fase especial, quase idílica, cuja sociabilidade seria muito diferente em relação aos anos posteriores, nos quais elas assumiriam uma vida profissional na instituição universitária. Ou seja, além dos elogios tecidos a boa parte do corpo docente dos cursos em que se formaram, instituindo-os como representantes do saber, elas também descrevem de forma positiva suas respectivas turmas, pois havia, conforme descreve Alice Canabrava, "oportunidade para a confraternização entre os estudantes das várias classes, com animadas conversas, jantares à noite (...)". Durante a graduação, as pioneiras afirmam que não havia distinção em suas classes, ou seja, homens e mulheres eram tratados de forma semelhante, sem diferenças, situação que mudou apenas quando começaram a dar os primeiros passos na vida profissional e acadêmica, uma vez que, neste contexto, entrou um elemento novo em cena: a competição.

Após os primeiros anos do curso, as historiadoras relatam mais dois acontecimentos que foram marcantes em suas trajetórias: a conquista do doutorado e a cátedra. Olga Pantaleão relata com certa tranquilidade as experiências do seu doutorado. Ao que tudo indica, ela não enfrentou grandes problemas para realizá-lo, pois recebeu ajuda financeira por meio de uma licença remunerada que lhe permitiu ausentar-se da FFCL, já que sua pesquisa foi feita na Biblioteca Nacional do Rio de Janeiro. Além disso, conta ela que recebeu auxílio para obter livros importados, com mediação do Conselho Britânico, necessários à sua pesquisa, cuja compra foi autorizada pelo secretário da USP. Olga concluiu seu doutorado em 1944, cuja tese chamou-se "A penetração comercial da Inglaterra na América Espanhola, de 1713 a 1783". Assim, num tempo em que fazer tese de doutorado era uma novidade, as "mulheres começaram a aparecer, participando de uma tradição de pesquisa 
que dura até hoje". Por outro lado, ela descreve as dificuldades que havia para as mulheres em relação à defesa da tese:

$\mathrm{Na}$ inscrição para o doutorado, as mulheres tinham as mesmas facilidades que os homens; mas talvez em certos casos tivessem mais dificuldades na defesa de tese, quando era possível alijar candidata indesejável. Contudo, no preparo do trabalho encontravam-se facilidades" (PANTALEÃO apud BLAY; LANG, 2004, p. 115).

Sobre estas dificuldades, Alice Canabrava narra detalhadamente os principais acontecimentos. Ao terminar o doutorado em 1942, cuja tese recebeu o título "O comércio português no Rio da Prata", a historiadora tentou o concurso para a Cadeira de História da América. Esse processo não surtiu resultados positivos por conta, segundo ela, de muitos obstáculos enfrentados. Alguns deles são narrados da seguinte maneira:

Outras armadilhas não lograram êxito e delas tive conhecimento depois de vários anos passados. A livraria onde comprava a maior parte dos livros para pagá-los mensalmente, ao todo ou em parte, foi avisada do risco em que incorria, mas não considerou advertência, com base na relação de muitos anos sem problemas. Um funcionário da Faculdade, como o próprio me contou em anos recentes, foi incumbido de me seguir diariamente e dar conta dos lugares que eu frequentava. Ouvi conselhos e insinuações de que não devia desafiar a hostilidade já construída: iria ser fatalmente reprovada. A minha resposta foi invariavelmente a mesma, sem qualquer argumento: "eu faço o concurso, caberá à banca me reprovar. (...) Deste modo, fechados e protegidos pela organização interna do grupo, os colegas do sexo masculino se favoreciam de uma estrutura legal, por eles elaborada, para servir aos seus interesses. Verificando-se o empate na votação, coube ao presidente da banca a decisão final e a tomou em favor do meu concorrente, sob a justificativa de que já se encontrava no exercício do cargo como professor contratado (CANABRAVA, 2003, p. 20; 24).

Mas, o esforço de Alice Canabrava não fora inócuo. Organizava-se em 1946 a Faculdade de Ciências Econômicas e Administrativas da Universidade de São Paulo, para a qual ela se transferiu de imediato. Tornou-se a primeira professora catedrática da Universidade de São Paulo em 1951, após concurso de provas e títulos. Dos professores economistas recebeu sempre "firme apoio" para se dedicar a História Econômica do Brasil de maneira que sua trajetória é narrada sem percalços quando elege este acontecimento, a transferência para a FCEA, como um dos principais contextos favoráveis à ascensão de sua vida profissional.

De fato, a ocupação da cátedra constituiu uma das principais dificuldades 
para as mulheres que desejavam fixar suas carreiras nos cursos universitários durante as primeiras décadas, desde a criação da USP. No máximo era possível conquistar o cargo de Professor Titular. Assim como Alice Canabrava, Olga Pantaleão também recorreu à mesma estratégia para se posicionar e consolidar sua profissão: realizou sua transferência para a Faculdade de Filosofia, Ciências e Letras de Marília, que estava no início de suas atividades, sendo Professora Titular entre 1959 a 1975, e diretora entre 1971 a 1975. Assim ela expõe suas lembranças acerca da Cátedra, em que discurso se cruza com o depoimento de sua colega de profissão, Alice Canabrava:

Finalmente, a Cátedra, posto final na carreira universitária na época, estava bem fora do alcance das mulheres: erguia-se uma muralha masculina contra a simples possibilidade. Nos anos 40, a única mulher catedrática na Congregação da Faculdade de Filosofia foi Noemy Silveira Rudolfer, que viera transferida do Instituto de Educação quando este foi extinto e, portanto, não tivera de pleitear a Cátedra. Durante quase um ano, de julho de 1946 a junho de 1947, mais uma mulher, eu mesma, pode aparecer nesse quadro, regendo interinamente a Cadeira de História da Civilização Moderna e Contemporânea. Durou pouco tempo: por pressão e ação do grupo masculino dominante no curso de Geografia e História, tive de deixar a Faculdade, tendo feito o restante de minha carreira fora da USP.

E, finalmente, uma mulher fez o concurso para a Cadeira de História da Civilização Americana: Alice Piffer Canabrava. Foi um acontecimento! Mas, apesar de ter obtido as melhores notas, não ganhou o concurso: a banca examinadora escolheu o segundo colocado em notas, homem, naturalmente, dando-lhe a Cátedra; esse absurdo era possível, então, por força do regulamento do concurso, o qual permitia à banca votar no candidato que ficaria em primeiro lugar. Isso foi tudo o que aconteceu, na década de 40, referente à ocupação da Cátedra pelas mulheres (PANTALEÃO apud BLAY; LANG, 2004, p. 113-114).

\section{Considerações Finais}

No livro Mulheres Públicas, a historiadora Michelle Perrot escreveu "ainda mais do que o espaço material, é a palavra e a sua circulação que modelam a esfera pública" (PERROT, 1998, p. 59). A ideia de que a natureza das mulheres as destine ao silêncio e à obscuridade esteve até pouco tempo atrás profundamente arraigada em nossas culturas. No caso brasileiro, nas primeiras décadas do século $\mathrm{XX}$, as mulheres estiveram absolutamente restritas ao espaço privado, permanecendo, durante muito tempo, excluídas da palavra pública e política. No entanto, podemos afirmar que um dos fatores que projetou as mulheres brasileiras ao espaço público foi o ingresso delas na universidade. Por meio dele, as mulheres se inseriram no mundo da escrita, da voz e, por consequência, da visibilidade. Conseguiram elas passar do oculto, 
que lhes era permitido, à visibilidade, que no início lhes foi contestada.

Os depoimentos das seis pioneiras revelam facetas de uma sociedade machista e patriarcal, que limitava as ações das mulheres na esfera pública. Em termos profissionais, eram poucas as oportunidades que elas tinham para desenvolver uma carreira que não se restringisse ao "cuidado do outro", como a de professora primária, enfermeira ou assistente social. Mas, a realização de um curso superior e a dedicação à carreira universitária modificaram, aos poucos, as relações de sociabilidade entre homens e mulheres na esfera pública. Nessa perspectiva, o trabalho intelectual e docente na universidade, em sua historicidade, está sendo considerado como uma atividade viva, um conceito circunscrito no espaço, no tempo e no corpo das agentes que nele se projetaram.

Nos depoimentos analisados, a carreira das pioneiras pode ser entendida não apenas como geradora de renda, mas também um meio de desenvolvimento de necessidades sociais, de autoestima e de conquista de espaços próprios. Para refletirmos essa questão, trazemos aqui o pensamento de Claude Dubar que defende a tese da centralidade do trabalho na vida pessoal e do lugar eminente das identificações profissionais na vida social, na qual o fato de ser reconhecido em seu trabalho, de travar relações, mesmo conflituosas, com os outros e de poder se empenhar pessoalmente em sua atividade é, ao mesmo tempo, construtor de identidade pessoal e de desenvoltura social. No caso das pioneiras, isso se reflete na maneira como elas escolheram expressar suas trajetórias profissionais, ou seja, seus discursos são marcados por uma satisfação e reconhecimento do seu próprio valor na constituição do campo disciplinar em que atuaram.

Os relatos revelam, também, que as trajetórias profissionais as conduziram para caminhos diversos e, por vezes, afastados da pesquisa e da docência. A multiplicidade do campo de trabalho dentro e fora das universidades é elucidativo, no sentido de como o prestígio e o reconhecimento podem ser construídos de outras formas e em outros círculos que superam o restritivo modelo da produtividade acadêmica. Muitas delas, senão a maioria, tiveram de ocupar cargos de chefia e de coordenação de Departamentos, Associações, Editoras e Conselhos, cujas atividades também configuraram empoderamento a essas mulheres.

Se por um lado focamos nossa análise naquilo que foi dito, por outro, deveremos também refletir naquilo que não foi dito, ou seja, em temas que ainda hoje geram dúvidas, conflitos e tensões para as mulheres que trabalham, independentemente das atividades profissionais que exercem. Trata-se de reconhecer as intersecções entre vida profissional e a vida familiar, isto é, o tensionamento entre a esfera pública e privada. Nos testemunhos estudados não há menções a respeito de como as pioneiras lidaram com aspectos condizentes ao casamento, filhos, vida pessoal e família. Pergunta-se: aquelas que foram casadas, elas tiveram apoio e reconhecimento de seus maridos? Quais foram as dificuldades enfrentadas na divisão dos papéis sociais do casal? A maternidade foi um fator impeditivo no exercício de algumas atividades ou ocupação de cargos? Deixaram de realizar algum curso de pós-graduação em outro país em virtude da família? Quais foram as negociações que realizaram no interior da família para que pudessem trilhar suas carreiras universitárias? 
Alguma delas abriu mão da vida amorosa e reprodutiva em detrimento da vida profissional? Enfim, foram estes os temas não problematizados em seus discursos.

Isso nos indica duas reflexões importantes. A primeira a de que existe uma concepção permanente de que o trabalho do professor universitário, do pesquisador e, sobretudo do intelectual, é algo dissociado de toda e qualquer atividade vinculada à vida doméstica e pessoal. Nesse sentido, o espaço universitário e o trabalho do intelectual são tratados como campos neutros, nos quais não há interferência de discursos, práticas e experiências da vida pessoal, social, econômica e cultural dos agentes que neles atuam. Em segundo, sabe-se que a entrada da mulher na vida pública, tanto a partir de sua incorporação no mercado de trabalho, como nos visíveis avanços de escolarização e na participação política, não foi acompanhada da inserção do homem nas responsabilidades com as tarefas reprodutivas, historicamente femininas. Com isso, consequentemente, defende-se que a inserção/acesso não é suficiente para afirmar o fim dos processos de dominação, exploração, característica da ordem patriarcal, principalmente em um espaço ocupacional, onde a alta qualificação, a formação continuada, a produção científica, a circulação nacional e internacional são inerentes à progressão e ascensão na carreira e acesso a melhores salários. Sendo assim, essas duas questões estão sendo tratadas com mais solidez apenas nos últimos anos, por meio dos estudos feministas, algo que na década de 1980 era inquestionável.

Por fim, os depoimentos aqui analisados pela ótica do discurso nos ajudam a penar como as jovens estudantes da década de 1930 perceberam que podiam construir suas vidas além dos limites consagrados para a mulher. Estudaram, formaram-se e, muitas delas, desenvolveram brilhantes carreiras universitárias. Possivelmente, enfrentaram conflitos entre o casamento e os filhos com a vida intelectual, o trabalho remunerado e a igualdade entre os sexos. Inserir-se nestas novas atividades foi, e é ainda hoje, muito custoso. Rupturas ou modelos alternativos de vivência e subjetividades não encontram apoio na sociedade que procura conservar seu modo de vida ordenado através da subalternidade feminina e que não oferece alternativas às profissionais, como, por exemplo, creches nos locais onde trabalham. Elas precisaram superar a ideologia patriarcal na qual foram educadas; lutar para abrir novos espaços de apoio que lhes permitissem trilhar as novas profissões e criar um espaço de visibilidade, no qual inclui o "poder da fala e da escrita", que lhes garantisse um lugar entre seus pares profissionais.

\section{Referências}

ARFUCH, Leonor. O espaço biográfico: dilemas da subjetividade contemporânea. Rio de Janeiro: EdUERJ, 2010.

AQUINO, Estela M. L. Gênero e Ciência no Brasil: contribuições para pensar a ação política na busca da equidade. In: Pensando Gênero e Ciência. Encontro de Núcleos e Grupos de Pesquisa - 2005-2006. Brasília: Secretaria Especial de Política para as Mulheres, 2006, p. 11-18. 
BLAY, Eva Alterman; LANG, Alice Beatriz da Silva Gordo. A mulher nos primeiros tempos da Universidade de São Paulo. Ciência e Cultura, v. 36, n. $12,1984$.

BLAY, Eva Alterman; LANG, Alice Beatriz da Silva Gordo. Mulheres na USP: horizontes que se abrem. São Paulo: Associação Editorial Humanitas, 2004.

CANABRAVA, Alice P. O caminho percorrido. Associação Brasileira de Pesquisadores em História Econômica. Setembro de 2003.

DUBAR, Claude. A Socialização: construção das identidades sociais e profissionais. São Paulo: Martins Fontes, 2005.

FOUCAULT, Michel. A ordem do Discurso. São Paulo: Ed. Loyola, 1998.

LIBLIK, Carmem Silvia da Fonseca Kummer. A participação das mulheres na construção do conhecimento histórico. Revista Feminismos, v. 2, n. 3, p. 55 68, 2014.

LIBLIK, Carmem Silvia da Fonseca Kummer. A formação e a profissionalização de professoras universitárias brasileiras (1960-1980). História Oral, v. 18, n. 2, p. 7 - 34, 2015.

LIMA, Nadia Regina Loureira de Barros. As mulheres nas ciências: o desafio de uma passagem. A passagem do privado para o público. In: COSTA, Ana Alice A.; SARDENBERG, Cecília Maria (Orgs.). Feminismo, Ciência e Tecnologia. Salvador: REDOR/NEIM-FFCH/UFBA, 2002, p. 51-65.

MAINGUENEAU, Dominique. Novas tendências em análise do discurso. Campinas: Martins Fontes, 1989.

ORLANDI, Eni. A linguagem e seu funcionamento. As formas do discurso. São Paulo: Editora Brasiliense, 1983.

PANTALEÃO, Olga. Olga Pantaleão. Historiadora. In: BLAY, Eva Alterman; LANG, Alice Beatriz da Silva Gordo. Mulheres na USP: horizontes que se abrem. São Paulo: Associação Editorial Humanitas, 2004.

PEROSA, Graziela. Educação diferenciada e trajetórias profissionais femininas. Tempo Social: revista de sociologia da USP, v. 20, n. 1, 2005.

PERROT, Michelle. Mulheres Públicas. São Paulo: UNESP, 1998.

SANTOS, Silmere Alves. Trabalho docente, família e vida pessoal. Permanências, deslocamentos e mudanças contemporâneas. São Paulo: Paco Editorial, 2015.

SCHMIDT, Benito. Luz e papel, realidade e imaginação: as biografias na história, no jornalismo, na literatura e no cinema. In: SCHMIDT, Benito (org.). 
Gênero e Trajetórias Acadêmicas das Primeiras Mulheres Universitárias

Brasileiras

O biográfico: perspectivas interdisciplinares. Santa Cruz do Sul: UNISC, 2000 .

TIBURI, Márcia. ET. AL. As Mulheres e a Filosofia. São Leopoldo: Ed. Unisinos, 2002.

TRIGO, Maria Helena B. Espaços e tempos vividos: estudo sobre os códigos de sociabilidade e relações de gênero na Faculdade de Filosofia da USP (1934-1970). 1997. Tese ( Doutorado em Sociologia) - Universidade de São Paulo, São Paulo. 